\section{A clínica de portas abertas: experiências e fundamentação do acompanhamento terapêutico e da prática clínica em ambiente extraconsultório}

Zamignani DR, Kovac R, Vermes JS, organizadores. São Paulo: ESETec; 2007. ISBN: 85-88303-80-9

O livro A clínica de portas abertas nos traz a fundamentação de abordagens relacionadas ao atendimento de pacientes portadores de quadros psicopatológicos variados em ambiente extraconsultório, através do referencial analítico-comportamental.

Para nós, profissionais que se deparam em sua prática diária com casos de difícil manejo, o livro se mostra uma importante ferramenta no sentido de embasar e validar as práticas de atendimento tidas como não convencionais (ambiente extraconsultório) em acompanhamento terapêutico.

O livro proporciona a visão sob o ângulo analítico-comportamental do quão rico pode ser o atendimento em setting não convencional, uma vez que, neste ambiente, segundo a análise dos próprios autores, ocorre aumento das possibilidades de efeito terapêutico do tratamento, gerado pela potencialização de estímulos (sociais e não sociais), bem como pelo acesso a reforçadores que produzem um aumento da variabilidade do comportamento terapeuta-cliente.

Sob a coordenação de Denis Roberto Zamignani, Roberta Kovac e Joana Singer Vermes, experientes terapeutas de referencial analíticocomportamental que compõe o Paradigma Núcleo de Análise do Comportamento, o livro se constitui em 17 capítulos inseridos em

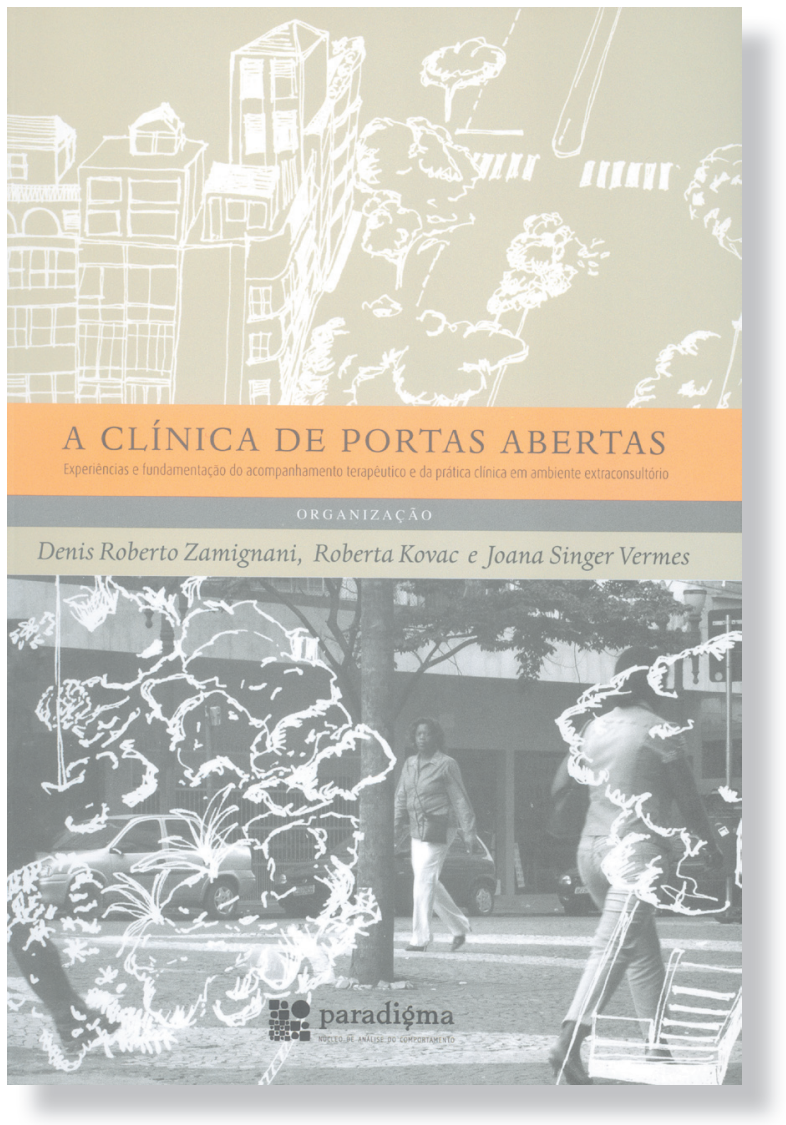

quatro sessões, sendo elas: 1) Fundamentos teóricos para o atendimento em ambiente extraconsultório; 2) Aspectos práticos envolvidos no trabalho extraconsultório; 3) Algumas propostas de intervenção em ambiente extraconsultório; e 4) A intervenção extraconsultório na atualidade: desenvolvimentos recentes e perspectivas. As referidas sessões e seus capítulos são permeados por interessantes relatos, referências (muitas delas dos próprios organizadores) e informações nas quais encontramos a fundamentação, a caracterização e o histórico do acompanhamento terapêutico, bem como a introdução de subsídios para o entendimento do referencial analítico-comportamental e sua aplicabilidade no setting extraconsultório. Todos esses pontos são colocados de forma bastante aprazível para profissionais que não possuem este referencial, incluindo ainda exemplos de casos clínicos de diferentes perfis diagnósticos nos quais se investiu em acompanhamento terapêutico com bons resultados; orientações no sentido de como se deve portar um profissional que se propõe realizar acompanhamento terapêutico perante a equipe de tratamento, o paciente e seus familiares; descrições de possibilidades de estruturação e funcionamento de equipes multiprofissionais e uma série de nuances fundamentada na literatura analíticocomportamental e também sob experiência pessoal relacionada ao atendimento, dúvidas e dia-a-dia de nós profissionais, experientes ou iniciantes, que atuam no sentido de melhorar a qualidade de vida de pessoas que nos procuram sob sofrimento psíquico.

Como profissional que atua em ambiente de Hospital-Dia, trabalhando em conjunto com equipe multidisciplinar no tratamento de pacientes portadores de transtorno mental grave e prolongado que necessitam estabilização e posterior inclusão em processo de reabilitação psicossocial, avalio o acompanhamento terapêutico e as práticas de atendimento extraconsultório como ferramentas fundamentais do processo terapêutico, uma vez que fornecem ao paciente, por meio de uma abordagem corpo-a-corpo, subsídios e parâmetros saudáveis a fim de melhorar de forma global o funcionamento do seu psiquismo.

Neste sentido, o livro A clínica de portas abertas traz importante contribuição para o enriquecimento do arcabouço teórico-prático de profissionais que se propõem a realizar o acompanhamento de casos com elevado grau de complexidade e também para aqueles profissionais que desejam enriquecer seu arsenal terapêutico para o tratamento de seus pacientes, sejam eles graves ou não.

Pedro Altenfelder Silva

Psiquiatra do Centro de Reabilitação e Hospital-Dia, Instituto de Psiquiatria, Hospital das Clínicas, Faculdade de Medicina, Universidade de São Paulo (USP), São Paulo (SP), Brasil 